\title{
No Rascunho do Novo Mundo: Os espaços e os personagens da França Antártica
}

Paulo KNAUSS*

Resumo: $O$ trabalho aborda a história do empreendimento colonizador francês na área da baía de Guanabara que se desenvolveu entre 1555 e 1560, conhecida pelo nome de França Antártica. A experiência francesa foi derrotada pela reação militar portuguesa, definindo um contexto de disputa colonial. A partir dos conflitos internos da empresa colonial francesa, a análise desenvolve a identificação de diferentes grupos na colônia francesa que se caracterizavam pela afirmação de projetos coloniais distintos, o que permite reconhecer 3 partidos da França Antártica. A análise considera que os projetos políticos se dividiam entre a questão do Estado, da religião e dos índios, identificando o sentido de cada um dos grupos constituídos entre os franceses. $\mathrm{O}$ argumento permite abordar a questão da localização de Henriville, a cidade colonial francesa, demonstrando que o domínio do espaço se traduziu como expressão dos projetos coloniais que se articularam nas terras do Novo Mundo. A pesquisa faz uso dos documentos da Inquisição portuguesa para identificar trajetórias individuais que não foram tratadas pela historiografia sobre a França Antártica.

Palavras-Chave: França Antártica; Colonização Francesa; Disputa colonial.

A França Antártica pode ser tratada como um evento de curta duração e, nesses termos, como fato efêmero da história colonial. Mesmo admitindo esse ponto de vista, há que se reconhecer sua intensidade.

* Departamento de História - Instituto de Ciências Humanas e Filosofia - UFF - 24210-380 - Niterói - RJ - Brasil. E-mail: pknauss@uol.com.br 
Entre 1555 e 1560, os acontecimentos em torno da ocupação francesa na Baía de Guanabara entrelaçaram diferentes fatos que caracterizam a historicidade da empresa colonizadora, demarcando o evento como expressão do seu tempo. Desse modo, destaca-se a liderança do comandante Nicolas Durand de Vilegagnon, cavaleiro da Ordem Malta, com voto de castidade e pobreza, assim como chama atenção a participação de protestantes franceses, conhecidos como huguenotes. As disputas religiosas européias transferiram-se para as terras do Brasil, instalando-se na Guanabara. A França Antártica representou um exercício de construção do mundo colonial, e as querelas que a envolveram permitem identificar diferentes projetos que rascunharam o Novo Mundo.

Levanto a hipótese de que no contexto da França Antártica, é possível observar três partidos que podem ser reconhecidos pelos seus personagens de destaque e igualmente por seus espaços.

Vasco Mariz, o conhecido biógrafo de Villegagnon, que tem insistido em afirmar a importância de Henriville, apresentando as evidências que comprovam a existência da "primeira aglomeração urbana européia", como ele diz. Depois dos franceses terem se estabelecido na atual ilha de Villegagnon, onde em 1555 instalaram o forte Coligny (onde hoje se localiza a Escola Naval), o comando francês teria ordenado em 1556 a construção de outro estabelecimento francês no continente, junto à foz do rio Carioca. Como anota Vasco Mariz, a história da cidade do Rio de Janeiro poderia ser pensada como a história de Buenos Aires, que tem dois processos de fundação e dois fundadores. Implícita nesse discurso está a idéia de colocar Villegagnon ao lado de Estácio de Sá no panteão da cidade. Contudo, a reação militar portuguesa contra os franceses na baía de Guanabara, sob as ordens de Mem de Sá, acabou com a presença francesa na região em 1560.

Segundo as indicações de André Thevet e as pistas das cartas de Villegagnon, Henriville estava localizada ao lado da foz do rio Carioca, que, antes dos sucessivos aterros, estaria situada 
hoje, ao final da Rua Barão do Flamengo. A posição era estratégica, pois a ilha não tinha fonte de água, e a localização de Henriville permitiria acesso a um manancial seguro aos franceses. Nas obras de André Thevet, o frade franciscano que ficou famoso por suas crônicas do Novo Mundo e da França Antártica, estão incluídos os conhecidos mapas da região, que surgiram depois de o franciscano ter acompanhado a primeira expedição francesa que chegou à Baía de Guanabara em 1555. Além disso, o local foi mencionado na carta de Villegagnon ao Duque de Guise, em 1557, a qual se encontra no Museu Naval do Rio de Janeiro, e também em panfleto de Pierre Richer, um dos líderes calvinistas que estiveram na ilha e que escreveu contra Villegagnon.

A referência permite que se reconheça a importância de Henriville para a interpretação dos acontecimentos, que se completam com a história da fundação da cidade do Rio de Janeiro. O domínio do espaço é uma expressão de como os projetos coloniais se articulam à terra do Novo Mundo.

Como indica o próprio Vasco Mariz, defensor da existência de Henriville, há quem discuta a existência de Henriville, como era o caso de Jean de Léry, outro conhecido cronista da França Antártica huguenote. Mesmo que a observação de Léry não seja verdadeira, mais importante é o fato de que Henriville representa o resultado do exercício de comando da França Antártica, a partir da liderança do cavaleiro da Ordem de Malta, Nicolas Durand de Villegagnon. A cidade projetada seria a sede da colônia francesa e se distinguiria do estabelecimento na ilha, que hoje chamamos de Villegagnon. As bases da vida na ilha dependiam dos indígenas por razões de abastecimento, tornando a ocupação vulnerável e dependente da gente nativa, ainda que servisse como abrigo militar e porto seguro, função importante para a realização do comércio colonial.

A carta de Villegagnon dirigida ao Duque de Guise, anotada a partir de Henriville, pode esclarecer o argumento. É possível colocar-se em dúvida o conteúdo da carta que certamente exagera o domínio francês sobre a área e sobre os indígenas. Porém, como projeção, Villegagnon apresenta sua 
empresa colonial como o centro de controle militar das terras da região da baía de Guanabara, e que tinha Henriville como eixo principal. Segundo o comandante francês, haveria em frente ao seu castelo de armas na ilha, um fortim de madeira com 60 homens no continente, que estariam dedicados também à pratica da agricultura, e ele anotou: "para viverem de seu trabalho". Em seguida, o cavaleiro francês anotou que tinha um plantel de 60 escravos de nativos, recolhidos em combates com inimigos. E escreveu ainda sobre o controle de fronteiras por meio de visitas repetidas à costa que ele teria ordenado, para estabelecer contato com "amigos de nossos vizinhos". Na carta, Villegagnon sustentava, igualmente, poder contar com um exército de mais três mil homens com base em forças indígenas aliadas. No horizonte, a carta se completa com a idéia de preparar expedições para encontrar o caminho para o Peru em busca de metais.

Estas notas da carta de Villegangon permitem caracterizar Henriville como projeto político. Observa-se que o projeto de cidade se organizava na apresentação do comandante como um povoamento protegido pelo seu caráter militar, mas também pela sua capacidade econômica, articulada pela produção voltada para garantir subsistência. A escravidão de nativos aparecia como possibilidade para sustentar a colonização com a mão-de-obra necessária à colonização européia. $O$ vínculo entre a dimensão militar e econômica garante a fonte dessa mão-deobra que vinha da capacidade militar e diplomática dos franceses de se envolverem nas rivalidades indígenas. Complementava esse quadro o fato da colônia surgir como ponta-de-lança do controle de fronteiras e de acesso aos caminhos que levavam às riquezas, representadas pelos metais andinos. A interlocução privilegiada com o Duque de Guise personagem da Igreja Católica e da política na França - confirma a marca de Estado de Henriville e de seu comandante. O quadro permite reconhecer um projeto estruturado para a exploração colonial em favor do fortalecimento do Estado. Henriville deveria ser a tradução do poder colonial francês, tal como o seu nome 
traduzia por sua identificação com o monarca chefe de Estado, Henrique II.

Paradoxalmente, a Henriville afirmada na descrição epistolar da França Antártica de Villegagnon é negada na crônica protestante da França Antártica de Jean de Léry, um dos cronistas da empresa colonial francesa que chegou à Baía de Guanabara em 1557, na $2^{\mathrm{a}}$ expedição comandada por Bois-LeComte, sobrinho de Villegagnon, e que trouxe para a França Antártica calvinistas, seguidores do movimento da reforma religiosa de Genebra. O cronista representa o ponto-de-vista huguenote, importante, sobretudo, depois da querela religiosa que dividiu o empreendimento colonizador francês.

Segundo narra o próprio Jean de Léry, a França Antártica dividiu-se após duas ceias, quando se desenvolveu uma disputa teológica entre o comandante Villegagnon, os pastores huguenotes e Jean Cointa, Senhor de Bolès, reunindo assim os homens de saber da colônia francesa. O último era um homem de armas e letrado, que, segundo o cronista, dizia-se doutor da Sorbonne; e os pastores possuíam reconhecida formação teológica. Villegagnon, por seu turno, era não apenas investido como Cavaleiro da Ordem de Malta, mas também havia sido antigo colega de universidade de João Calvino. O encontro destes personagens conduziu a uma discussão doutrinária tensa acerca da transubstanciação e consubstanciação do pão e do vinho da eucaristia. Segundo Léry, a discordância teológica revelou a posição clara dos ministros protestantes de que a máxima "este é o meu corpo, este é o meu sangue" era uma imagem figurada. Ao contrário, Villegagnon e Cointa consideravam-na válida pelo efeito mágico que promovia ao estabelecer o contato com o corpo e com o sangue de Cristo.

Interessa aí destacar o fato de que a querela teve conseqüências ao dividir a colônia em grupos identificados por suas lideranças, ou três partidos coloniais, como prefiro dizer: o partido de Villegagnon; o partido dos pastores calvinistas; e o partido de Jean Conta, Senhor de Bolès. Cada um desses grupos se recolheu em áreas diferentes da França Antártica. Cada um desses grupos se identifica por suas lideranças, mas igualmente 
pelos espaços diferentes da França Antártica que terminaram constituindo.

O partido de Villegagnon, identificado pelo projeto de Henriville, manteve-se na ilha com o comandante e pressupondo sua hegemonia sobre os nativos da terra.

O grupo liderado pelos calvinistas terminou se retirando para o continente, localizando-se no local que Léry chamou de La Briqueterie, ou a Olaria. Chama atenção o fato de que todas as indicações do cronista apontam para que este espaço estivesse no mesmo lugar que a Henriville projetada. O cronista genebrino não reconhecia o lugar pelo mesmo topônimo, nomeando de outro modo a mesma terra. É possível que a confusão fosse provocada pela evidência de que no lugar havia mesmo uma olaria - aliás, elemento importante para expansão da infra-estrutura básica do projeto colonial no continente. No entanto, mais do que uma mentira, o topônimo acentuado por Léry, nega o sentido do projeto colonial de Henriville e fixa outra projeção sobre o espaço colonial. Assim, a afirmação de outro nome para caracterizar o mesmo lugar pode ser vista pela intenção de atribuir ao espaço outro sentido como forma de traduzir um projeto colonial particular. O topônimo escolhido identifica uma atividade humana local, e não alude à presença monárquica de Estado europeu. $\mathrm{O}$ nome separa a terra de sua identidade de Estado e da continuidade das estruturas do Velho Mundo. Ocorre aí um contraste, que demarca o sentido político de um projeto colonial huguenote. Tal projeto se estrutura ainda pelo fato de os calvinistas franceses permanecerem nesse sítio, ao menos na crônica de Léry, separados de outros franceses nãocalvinistas e evitando compartilhar a vida com a gente nativa da terra, formando um grupo individualizado. Em relação aos nativos, os huguenotes praticavam uma pedagogia da conversação, tal como indica Frank Lestringant, que caracterizava um diálogo de consciências e permitia uma convivência sem que os mundos sociais se mesclassem, mantendo a devida distância entre o cristianismo dos europeus e o gentilismo dos nativos da terra do Novo Mundo. Essa 
distância, no entanto, não impediu que os huguenotes contribuíssem decididamente para a elaboração dos traços do bom selvagem ao caracterizar o indígena e relativizar a civilização européia. O reconhecimento da diferença, porém, certamente foi decisivo para que os huguenotes, ao abandonarem a ilha da colônia francesa, escolhessem um lugar à parte no continente, evitando compartilhar a vida com os nativos.

Por fim, o terceiro partido que se formou no seio da França Antártica identificou-se pela liderança de Jean de Cointa, ou Senhor de Bolès. Ainda que nos faltem elementos para caracterizar quantos homens compunham este grupo, sabemos que se retiraram da ilha sob o comando de Villegagnon, mas também não foram compartilhar a convivência com o grupo liderado pelos pastores protestantes. Os homens deste grupo juntaram-se aos índios do continente, passando a viver sob as condições de vida da gente da terra. Aproximaram-se, então, da gentilidade, expressão de época que caracterizava a marca da adoção dos hábitos indígenas. Nessa atitude poderiam lembrar a figura dos intérpretes, que tiveram papel-chave na realização do escambo colonial. Mas, neste caso, a recusa ao comando colonial e a busca de soluções individuais permite antes associar o grupo aos desertores, personagens típicos das empresas de navegação colonial, que preferiam a aventura individual de embrenhar-se no Novo Mundo a permanecer, ou retornar, às estruturas sociais do Velho Mundo.

A trajetória de Cointa pode caracterizar um modo particular de elaborar um projeto colonial como projeto individual, independente do Velho Mundo, e autônomo em relação a estruturas sociais abrangentes. João de Cointa entrou para os anais da história ao ser envolvido em um processo inquisitorial, deixando o registro de sua experiência pessoal. Depois de romper com o comando de Villegagnon, foi viver entre os índios tamoios, e ao acompanhar um dos confrontos militares dos índios com as forças lusitanas mais ao sul, terminou passando para o lado dos portugueses, indo ficar algum tempo em São Vicente. Como informante, colaborou com as forças 
lusitanas para o derradeiro ataque militar às forças francesas da baía de Guanabara em 1560. Porém, o personagem terminou sendo denunciado ao Santo Ofício, sendo envolvido na malha da Inquisição portuguesa. Transferido para Lisboa, 0 francês terminou seus dias Goa, conectando as partes do império colonial lusitano.

A leitura dos autos de seu processo inquisitorial permite destacar um enunciado: a curiosidade. O mesmo enunciado que aparece na relação da expedição de Gonneville de 1503, conectando também personagens de saberes diferentes, mas que aparecem reunidos na leitura de seus depoimentos. Talvez, possamos localizar aí o sentido de seu projeto colonial individual. Seu espaço, se num primeiro momento foi o espaço dos índios, noutro momento pode ser o dos portugueses. Movido pela curiosidade, o João de Cointa, ou João de Bolès, dos autos da Inquisição portuguesa, era movido por um projeto desgarrado de ordens coletivas e estruturas sociais, em busca de um espaço próprio de mobilidade social. Lucien Febvre, em uma das passagens de sua obra, caracteriza o século XVI como o tempo em que a Igreja se imiscui em tudo. Considerando que os vínculos entre religião e Estado eram fortes naquele tempo, pode-se imaginar que o espaço de mobilidade individual que conduzia o desertor, ou a gentilidade, ou a curiosidade era um espaço não dominado pelo Estado ou pela Igreja.

Por meio da Inquisição portuguesa é possível conhecer ainda outro personagem da França Antártica. Aliás, sua indicação consta no livro da Primeira Visitação do Santo Ofício ao Brasil, conhecido também como Confissões da Bahia. Nesse livro há referência a três franceses denunciados, entre um número ainda maior de estrangeiros, que se constituíram sempre, de acordo com as conjunturas em objeto da Inquisição portuguesa, tal como se verifica em pesquisa de Isabel Braga. Entre eles, há menção ao caso de Pero da Vila Nova, um francês nascido em Provins, suposto filho do cavaleiro Nicolau de Colenhi. Notam-se nestas referências certas raras coincidências, pois a cidade indicada como lugar de nascimento de Vila Nova é 
a mesma cidade de Villegagnon. Além disso, a indicação da paternidade sugere parentesco com o almirante Coligny, mas que não tinha o pré-nome indicado. $O$ pré-nome indicado, no entanto, era o mesmo de Villegagnon. Observa-se, portanto, uma possível confusão de dados, no que se refere à caracterização do denunciado da Inquisição. Certo é que se tratava de um francês que se encontrava vivendo no Brasil em 1592, época de sua confissão. Vivia como morador de Sergipe do Conde, tinha cerca de 55 anos, e era casado com Leonor Marques de Mendonça, cristã-velha.

Segundo os autos do processo de Pero de Vila Nova, existentes na Torre do Tombo, importa ressaltar o fato de que o francês veio para o Brasil em 1557, na $2^{\mathrm{a}}$ expedição de colonos da França Antártica, quando tinha cerca de 20 anos, quando conviveu com "luteranos", como se menciona em termo genérico nos autos os calvinistas protestantes. Em sua confissão, consta que teria vivido na ilha do forte Coligny cerca de 11 meses. Segundo os autos, depois de conviver sob imposições dos chamados "luteranos", o depoente menciona a mesma querela sempre citada sobre o pão e o vinho e que dividiu a colônia. Pero de Vila Nova abandonou a ilha e passou nove ou dez meses vivendo com os índios, chamados "negros gentios" no processo, antes de "fugir para os cristãos portugueses", tal qual consta nos autos. Pero de Vila Nova repete o percurso de João de Bolès, acompanhando os mesmos passos. Porém, demorou a ser pego pela Inquisição, e terminou sendo liberado ao final do processo com a pena de fazer a abjuração de Levi e com a obrigação de se confessar, devendo respeitar as penas colocadas por seus confessores. ${ }^{1}$

Em sua confissão, menciona ainda dois outros nomes, Martim Paris e André de Fontes, que também teriam ficado no Brasil. O primeiro, segundo consta, diziam estar casado, vivendo no Rio de Janeiro, e o segundo, também casado, residindo em São Vicente. Estes nomes se caracterizam pela ausência da marca do personagem do saber, por contraste com as lideranças da França Antártica. Não há notícias de que tenham estudado em universidade, ou que tenham tido formação teológica 
específica. Nesse sentido, distinguem-se de Villegagnon, Richer e Cointa. Mas possuem uma característica inusitada: estabeleceram-se e enraizaram-se nas terras do Brasil, encontrando o seu lugar nos interstícios do mundo colonial português. Sem lugar para um projeto colonial arquitetado pelo discurso intelectual, estes homens comuns da colonização da terra do Brasil ocuparam um espaço social próprio no Novo Mundo que se constituía como rascunho de um processo histórico.

KNAUSS, Paulo. In the Sketch of the New World: The spaces and the individuals of the French Antarctic. História, v.27, n.1, p.143$154,2008$.

Abstract: The work approaches the history of the French colonization undertaking in the Guanabara Bay area that developed itself between 1555 and 1560, and became known as the French Antarctic. The French experiment was defeated by a Portuguese military reaction, which defined a context of colonial dispute. From the internal conflicts of the French colonial business, the analysis develops the identification of different groups within the French colony that were characterized by the affirmation of distinct colonial projects, which allowed for the recognition of 3 factions of the French Antarctic. The analysis considers that the political projects divide themselves among the question of the State, religion and the Indians, identifying the sense of each one of the constituted groups amidst the French. The argument permits approaching the question of the localization of Henriville, the French colonial city, showing that the domain of the space translated itself as an expression of the colonial projects that articulated themselves in the lands of the New World. The research makes use of documents from the Portuguese Inquisition to indentify individual trajectories that were not treated by historiography with respect to the French Antarctic. 
Keywords: French Antarctic; French Colonization; Colonial dispute.

\section{REFERÊNCIAS BIBLIOGRÁFICAS}

BRAGA, Isabel M. R. Mendes Drummond. Os estrangeiros e a Inquisição portuguesa (século XVI-XVIII). Lisboa, Hugin, 2002.

KNAUSS DE MENDONÇA, Paulo. O Rio de Janeiro da pacificação: franceses e portugueses na disputa colonial. Rio de Janeiro: Prefeitura da Cidade, 1991. (Bilbioteca Carioca).

LESTRINGANT, Frank. Le huguenot e le sauvage: l'Amérique et la controverse coloniale; au temps des guerres de religion. Genève, Droz, 2004.

MARIZ, Vasco \& PROVENÇAL, Lucien. Villegagnon e a França Antártica. Rio de Janeiro: Nova Fronteira, 2000.

VAINFAS, Ronaldo (org.). Confissões da Bahia. São Paulo: Companhia das Letras, 1997.

\section{NOTA}

1 Registro meus agradecimento a Rogério Ribas, meu colega no departamento de História da Universidade Federal Fluminense, que localizou este processo no Arquivo da Torre do Tombo e trouxe em microfilme. A leitura, no entanto, foi permitida ainda pela transcrição de Rodrigo Bueno Abreu, que utilizou o documento em sua monografia de Bacharelado na mesma universidade. Aos dois colegas, devo minha gratidão.

Artigo recebido em 03/2008. Aprovado em 07/2008. 
